\title{
PERANAN GURU PENDIDIKAN AGAMA KRISTEN (PAK) DALAM PENGINJILAN
}

\author{
Megawati Manullang \\ Institusi Agama Kristen Negeri Tarutung \\ Email: megamanullang2@gmail.com
}

\begin{abstract}
Abstrak : Media sosial sering memberitakan tentang perbuatan dari beberapa guru yang tidak terpuji, khususnya perbuatan yang merugikan para muridnya sendiri. Baik itu tindakan pemerkosaan, pemukulan, pemerasan dalam bidang materi, dan masih banyak lagi kasus yang lain. Padahal seorang guru diharapkan menjadi teladan, baik dalam perkataan, tingkahlaku yang menjadi berkat bagi siswa. Terutama profesi sebagai guru Pendidikan Agama Kristen (PAK) tidak sama dengan guru-guru umum lainnya, guru PAK memiliki tugas dan tanggung jawab yang lebih berat, bukan hanya sekedar memberikan informasi dan ilmu pengetahuan kepada peserta didik tetapi yang paling utama adalah membawa peserta didik mengalami perjumpaan dengan Kristus dan memiliki hidup baru di dalam Kristus. Maka untuk mencapai hal tersebut guru PAK wajib melaksanakan penginjilan.
\end{abstract}

\section{Kata kunci: Guru PAK, Penginjilan}

\begin{abstract}
Social media often notifies that some teacher did praiseworthy deeds, especially actions that harmed students. Those behaviors were including rape, beatings, extortion in the field of material, and many other cases. Actually, a teacher is expected to be a role model by their words and behavior blessing students. Especially, the profession as a Christian religious education teacher is not same as other teachers. Christian religious education teachers have more difficult duties and responsibilities which not only providing information and knowledge to students, but they also bring students to experience a special meeting with Christ and have a new life in Christ. Therefore, to meet this main responsiblities, Christian religious education teacher must carry out evangelism.
\end{abstract}

Keywords: Christian religious education teacher; evangelism; students

\section{PENDAHULUAN \\ Latar Belakang Masalah}

Akhir-akhir ini sering kali muncul berita di televisi maupun surat kabar yang memberitakan tentang perbuatan dari beberapa guru yang tidak terpuji, khususnya perbuatan yang merugikan para muridnya sendiri. Baik itu tindakan pemerkosaan, pemukulan, pemerasan dalam bidang materi, pembocoran soal ujian dan masih banyak lagi kasus yang lain. Perbuatan yang demikian menunjukkan bahwa profesi sebagai guru bukan untuk melayani.

Sehubung dengan hal tersebut, seorang guru diharapkan memiliki berbagai aspek keutamaan yaitu, ketepatan, kesabaran, kesederhanaan, menghargai profesi, berprasangka yang baik, mengontrol kompetensi, melaksanakan tugas dengan baik, membuat persiapan yang baik, dan memiliki semangat iman. Seorang guru dituntut untuk memiliki karakter hidup yang baik, karena guru harus menjadi teladan bagi para muridnya.

Menjadi guru Pendidikan Agama Kristen (PAK) merupakan suatu panggilan khusus. Profesi sebagai guru PAK tidak sama dengan guru-guru umum lainnya, guru PAK memiliki tugas dan tanggung jawab yang lebih berat, dalam hal ini guru PAK bukan hanya sekedar memberikan informasi dan ilmu pengetahuan kepada peserta didik tetapi yang menjadi tugas dan tanggung jawab guru PAK yang paling utama adalah membawa peserta didik mengalami perjumpaan dengan Kristus dan memiliki hidup baru di dalam Kristus. Maka untuk mencapai hal tersebut guru PAK wajib melaksanakan penginjilan 
ketika menyampaikan materi pelajaran yang berkaitan dengan pokok bahasan dan juga di luar jam pelajaran.

Dalam tugas penginjilan, bukanlah hanya kewajiban pendeta maupun para penatua gereja, tetapi guru PAK juga ikut mengambil bagian dalam penginjilan. Penginjilan yang dilakukan oleh guru PAK bukan hanya pada saat jam pelajaran PAK dan bukan hanya peserta didik sebagai objeknya, tetapi lebih dari itu, guru PAK dapat menyadari hal tersebut dan mau membuka hati untuk melaksanakannya.

\section{Guru Pendidikan Agama Kristen (PAK) dalam Penginjilan}

2 Korintus 5:17-21

"Jadi siapa yang ada di dalam Kristus, ia adalah ciptaan baru; yang lama sudah berlalu, sesungguhnya yang baru sudah datang. Dan semuanya ini dari Allah, yang dengan perantaraan Kristus telah mendamaikan kita dengan diri-Nya dan yang telah mempercayakan pelayanan pendamaian itu kepada kami. Sebab Allah mendamaikan dunia dengan diri-Nya oleh Kristus dengan tidak memperhitungkan pelanggaran mereka. Ia telah mempercayakan berita pendamaian itu kepada kami. Jadi kami ini adalah utusanutusan Kristus, seakan-akan Allah menasehati kamu; dengan perantaraan kami; dalam nama Kristus kami meminta kepadamu; berilah dirimu didamaikan dengan Allah. Dia yang tidak mengenal dosa telah dibuat-Nya menjadi dosa karena kita, supaya dalam Dia kita dibenarkan oleh Allah"

Kata "Penginjilan" (bahasa Inggris "evangelism"; dalam bahasa Belanda "apostolat". Menurut Homrighausen (2014: 178) Penginjilan adalah pemberitaan Kabar Kesukaan, yang memanggil manusia untuk mempercayai segala janji Allah dalam Yesus Kristus, sehingga manusia akan menyesalkan dosadosanya dan hidupnya yang buruk, lalu berserah kepada Yesus Kristus selaku Penebus dan Raja, mencari persekutuan dengan Dia setiap hari, dan melayani Dia dalam segala lapangan hidupnya dengan patuh dan setia. Injil Yesus Kristus harus diberitakan sedemikian rupa hingga memulihkan manusia. Injil mengerjakan pertobatan bagi seseoraang. Injil mengadili manusia dan menyelamatkannya. Luther pernah mengatakan: "Injil mematikan Adam lama, dan membangkitkan Adam baru"

Penginjilan itu tidak lain daripada membawa Yesus Kristus kepada sesama kita, sehingga mereka dapat berjumpa muka dengan muka, dalam suatu pertemuan perseorang yang mesra. John Mott pernah berkata: "Penginjilan itu berarti memperkenalkan Yesus Kristus, sehingga Ia dikasihi, dipercayai dan ditaati". Penginjilan itu ialah pengasihan dan pertolongan persaudaraan kita terhadap orang-orang musafir pada perjalanan yang sukar melalui hidup ini ke arah Sorga Rumah Bapa.

Bagi umat Allah sebagai pelaksana penginjilan adalah suatu tugas. Tugas ini diamanatkan oleh Allah di dalam Yesus Kristus (Mat 28: 18-20). Tugas ini adalah tugas apostolic (Yoh 17:18) yang diberikan kepada umat Allah sebagai kelompok yang terdiri dari pribadi-pribadi. Dengan demikian sesungguhnya tugas ini adalah tugas tiap-tiap orang yang sudah menikmati kasih Allah (Yoh 1:12; 1 Pet 1:9-10). Dalam tugas yang dimandatkan itu telah ada tujuan yang pasti, yaitu: "Menjadikan murid-murid darin segala bangsa" (Mat 28: 19).

Dalam hal ini guru PAK sangat berperan dalam membawa jiwa untuk mengenal Kristus sebagai Tuhan dan juruselamat.

Pendidikan Agama Kristen adalah pendidikan yang menyadarkan setiap orang akan Allah dan kasih-Nya dalam Yesus Kristus, agar mereka mengetahui diri mereka yang sebenarnya. Keadaannya, bertumbuh sebagai anak Allah dalam persekutuan Kristus, memenuhi panggilan bersama sebagai murid Yesus di dunia dan tetap percaya pada pengharapan Kristen.

Selanjutnya Naingolan menyatakan isi pengajaran Pendidikan Agama Kristen di sekolah untuk mendukung penginjilan kepada siswa-siawa antara lain:

\section{Pengajaran Iman Kristen}


Pengajaran iman Kristen adalah untuk membantu peserta didik dalam perjumpaanny dengan tradisi Kristiani dan wahyu Allah guna memahami, memikirkan, menyakini dan mengambil keputusan berdasarkaan isi pengajrannya.

2. Pengembangan Spritual

Membantu peserta didik untuk mengembngkan rohaninya dalam sikap dan perbuatan dan mengarah kepada pembentukan spiritual serta membimbingnya kearah kedewasaan rohni. Dengan demikian setiap orang percaya dapat memiliki kedewasan iman.

3. Pembebasan

Pendidikan Agama Kristen bertujuan untuk mendorong agar peserta didik dapat menghayati gaya hidup krustiani melalui keterlibatannya dalam berbagai kehidupan di sekolah, di kelurga ataupun di masyarakat lingkungannya.

4. Relevaansi

Pendidikan Agama Kristen haruslah relevan dengan kebutuhan-kebutuhan iman masa kini, agar peserta didik dfapat mengaflikasikannya dalam tantangan dan keadaan yang dihadapi.

5. Kecintaan kepada firman Allah Pendidikn Agama Kristen hendaknya dapat membawa peserta didik kepada keecintaan kepada firman Allah dan menjadikan firman itu sebagai pedoman kehidupan terhadap Tuhan, sesame Maupin diri sendiri.

6. Membaharui sikap dan Prilaku

Pengajaran Kristen haruslah dapat memperbaharui sikap dan perilaku orang-orang percaya dan mampu menjadikan hidupnya sebagai ciptaan baru (2 Kor 5: 17), dapat memuliakan Allah dan menjadi berkat bagi sesamanya.

7. Penemuan Jati diri

Pendidikan Agama Kristen adalah merupakan pencarian jati diri sehingga dapat menemukan kebenran Allah di dalam dirinya dan member tempat kepada Roh Kudus dalam pengembangan rohani setiap pribadi.

8. Pentransferan Pengetahuan dan Nilainilai Kristiani
Pendidikan Agama Kristen adalah pentransferan pengetahuan, siat, watak, iman dan nilai-nilai, serta merupakan proses perubahan dalam diri dan pengembangan pribadi sehingga memiliki otoritas dan kemandirian iman dalam hidupnya.

9. Prinsip Integrasi.

Di manapun Pendidikan Agama Kristen dilaksanakan haruslah senantiasa kontekstual dengan lingkungannya dan meniliki ketertarikan dengan banyak hal"

\section{Metode Penginjilan}

Mengabarkan Injil secara pribadi adalah pemberitaan Injil dalam hidup sehari-hari, dimana seorang yang telah mengenal Kristus berupaya memperkenalkan Kristus kepada orang lain dan mengajaknya menerima Kristus. Lalu orang yang baru menerima Kristus itu dibimbing menjadi saksi Kristus pula.

Penginjil harus mengenal kepribadian seseorang, dan menyesuaikan pola pendekatan dan bobot berita Injil yang akan disampaikan dengan kepribadian orang itu. Akan hal ini Paulus berkata: "Aku menjadikan diriku hamba dari semua orang, supaya aku boleh memenangkan sebanyak mungkin orang" ( 1 Kor 9:1923).

Contoh mengabarkan Injil secara pribadi

"Tuhan Yesus dengan Wanita Samaria" (Yoh 4)

Ada beberapa hal menjadi pelajaran dari metode Yesus dalam peristiwa ini yang penting untuk diperhatikan, yaitu:

1. Yesus sengaja mencari wanita itu (4:4)

2. Yesus tidak terikat pada tradisi dan tidak terpengaruh oleh diskriminasi rasial (4:9)

3. Yesus memilih waktu yang tidak akan menimbulkan salah paham (4:6)

4. Yesus seorang diri bercakap-cakap dengan pendengar-Nya (4:8)

5. Pendekatan Yesus pada hal rohani adalah wajar dan bijaksana; misalnya, Ia minta tolong pada wanita itu (4:7) dan barulah Dia mengarahkan 
percakapan dari air minum kepada air hidup

6. Yesus tidak dibelokkan dari tujuan-Nya oleh pertanyaan mengenai agama (4:2024)

7. Yesus memaparkan rahasia keinginan hati perempuan itu (4:15)

8. Yesus menunjuk kepada dosanya (4:1618)

9. Yesus memperkenalkan diriNya sebagai Mesias (4:26)

\section{Perkunjungan Rumah}

a. Dasar perkunjungan rumah

Pada zaman Perjanjian Lama Allah mengunjungi umat-Nya melalui Musa dan nabi-nabi. Demikian juga pada zaman Perjanjian Baru khususnya melalui Kristus (Luk 7:36-50;10:3842). Perhatikanlah perkunjungan Paulus dari rumah ke rumah di Efesus (Kis 20:20).

b. Macam-macam Perkunjungan

Ada tiga macam perkunjungan rumah:

1. Perkunjungan dari rumah ke rumah Tujuannya adalah untuk menciptakan hubungan yang akrab dengan masyarakat, guna memungkinkan penyampaian kabar baik di dalam rumah mereka. Misalnya mengunjungi suatu Rukun Tetangga (RT).

2. Perkunjungan untuk kesejahteraan orang-orang tua

Tujuannya adalah untuk mengabarkan Injil Kristus kepada orang tua dan juga untuk menolong mereka dalam kesehatannya dan menemukan kesejahteraannya.

3. Perkunjungan kepada orang-orang sakit Dapat diadakan doa khusus bagi orangorang sakit dan memberi mereka motivasi supaya tetap berpengharapan memperoleh kesembuhan dari Kristus

\section{Beberapa petunjuk pokok}

Kalau kesempatan itu sudah tiba, Ellis mengemukakan (1999:133) beberapa petunjuk pembimbing yang perlu di pedomani, yaitu: a. Carilah tempat dan waktu yang tenang untuk bicara. Hindarilah hal-hal yang dapat mengganggu pembicaraan itu.

b. Sediakan Alkitab

Alkitab mutlak harus ada guna memungkinkan dapat bersama-sama melihat ayat-ayat inti. Dari awal pembicaraan harus jelas, bahwa berita yang disampaikan bukan dari diri sendiri, melainkan firman yang berasal dari Tuhan.

c. Berita jelas dan sederhana

Sebisa mungkin dalam pemberitaan yang dilakukan adalah sederhana dan mudah dipahami.

d. Lugas dan sopan

Jangan lupa seorang yang belum percaya masih "buta" adalah suatu kebodohan kalau kita kehilangan kesabaran karena ia "buta" sehingga tidak dapat melihat. Baiklah kita berusaha tidak marah. Hindarilah perdebatan apalagi perbantahan.

e. Kesaksian pribadi menopang dan menghidupkan pemberitaan

Kita dipanggil bukan hanya untuk menjelaskan siapa Kristus, apa yang telah dikerjakan Kristus dan apa yang dapat diperbuat-Nya untuk sahabat kita. Tapi kita juga wajib memberikan kesaksian kita pribadi tentang pengalaman kita sendiri dengan Kristus.

f. Tetap memandang kepada Tuhan selama percakapan

Hanya Roh Kudus-lah yang dapat membuka mata hati orang yang belum percaya. Kiranya Tuhan berkenan menggunakan kata-kata kita membuka mata rohani orang itu. Tuhan sendirilah yang dapat membuka mata hari orang yang "buta" itu.

\section{Aplikasinya Bagi Guru PAK}

Yang pertama yang harus dilakukan guru PAK sebelum menginjili murid didiknya maupun orang lain adalah ia harus terlebih dahulu hidup baru (bertobat). Tidak akan berhasil penginjilan yang ia lakukan kalaulah ia juga belum hidup baru (dilahirkan kembali), ia tidak akan dapat membawa peserta didik mengalami perjumpaan dengan Kristus. Hal demikian sama halnya orang buta 
menuntun orang buta. Dalam hal ini guru PAK bukan hanya menjadikan peserta didiknya menjadi manusia yang sopansantun, memiliki kesusilaan yang baik, tetapi guru PAK harus mampu membuat peserta didik menyambut Kristus sebagai Tuhannya.

Di dalam pengajarannya, berarti guru PAK mengajarkan mengenai isi kepercayaan Kristen dan bagaimana seharusnya seorang Kristen hidup dalam dunia ini. Pengajaran itu harus menguraikan apakah yang dipercaya dan dibuat oleh orang yang telah menyambut berita kesukaan itu. Sebenarnya tidak ada perbedaan yang tajam antara penginjilan dan pengajaran PAK, tetapi kedua ini erat hubungannya.

Guru PAK harus memberikan pendidikan yang takhluk kepada pimpinan Roh Tuhan dan yang bercorak penginjilan pula, karena guru PAK bukan berarti menyampaikan beberapa teori saja, atau menguraikan ajaran dan kesusilaan Kristen secara ilmu pengetahuan yang abstrak, guru PAK seharusnya bukan saja menuju otak dan akal para murid, tetapi juga seluruh alam perasaan dan kehendak mereka. Dalam pengajarannya, guru PAK harus sanggup menawan jiwa peserta didik bagi Tuhan.

\section{Tujuan Penginjilan}

Menurut Nainggolan (2009:79) tujuan menginjili melalui Pendidikan Agama Kristen adalah:

\section{Pertobatan}

Firman Allah yang diajarkan bertujuan menghasilkan perubahan bagi setiap orang, yaitu perubahan yang dikerjakan oleh kuasa firman Allah. Pertobatan menyangkut penyesalan dan kesedihan atas perilaku yang lama (2 Kor 7:9); berpaling dari perilaku dosa (Kis 8:22) kepada hidup yang baru di dalam Kristus Yesus (Mrk 1:15).

2. Pertumbuhan Rohani

Pertumbuhan rohani terlihat dari dua aspek yaitu: aspek vertikal yakni diperbaharuinya hubungan seseorang dengan Allah yang dikokohkan melalui firman Allah dan doa. Aspek horizontal yakni ditandai dengan praktek iman dalam hubungannya dengan sesama. Pertumbuhan rohani terjadi harus terus-menerus dan semakin terlihat dalam kehidupannya sehari-hari.

3. Pemuridan

Pengertian murid dibagi menjadi dua pengertian yakni: bahwa semua orangorang percaya adalah murid-murid Kristus, mereka dipanggil untuk mengikut Tuhan dengan setia dan dapat mewujudnyatakan imannya sebagai pengikut Kristus. Dikatakan juga sebagai murid berarti, orang-orang percaya dengan rela hati melayani Tuhan secara khusus dan menjadi pelayan-pelayan Kristus. Sebagai murid-murid Kristus, peserta didik haruslah dibawa kepada kesetiaan menjadi murid Kristus.

4. Pembentukan Spiritual

Melalui PAK peserta didik harus mengalami pembentukan rohani yang sungguh-sungguh. Berarti dalam hal ini, peserta didik memperoleh kekuatan atau roh yang memberi daya tahan untuk mempertahankan, mengembangkan, dan mewujudkan kehidupannya. Spiritual memungkinkan orang-orang percaya memiliki, kekuatan, ketabahan, kesabaran, kebaikan, kesucian dan ketaatan di dalam Yesus Kristus.

\section{Tanggung Jawab Umum}

Setiap orang Kristen dipanggil untuk menjadi saksi Yesus Kristus (Kis 1: 8). Masing-masing bertanggung jawab mengupayakan orang lain bagi Kristus. Kita mempunyai paling sedikit empat kewajiban terhadap orang yang akan kita bawa kepada Kristus.

1. Berdoa

Catatlah namanya (atau nama mereka) dan doakanlah dengan teratur, khusunya memohon supaya mereka bertobat.

2. Teladan

Mereka akan segan dan acuh mendengarkan kata-kata kita mengenai Yesus Kristus, jika mereka tidak lebih dahulu menyaksikan Yesus dalam 
hidup kita. Teladan kekristenan tidak dapat dipaksakan atau dibuat-buat, melainkan wajar. Bahkan kita sendiri sukar menyadarinya (Mat 5:16), karena itu adalah dampak dari hidup kita pribadi dengan Kristus.

3. Bersahabat

Bila kita mau menjadi sahabat seseorang, kita wajib berbicara kepadanya tentang

Kristus.

Persahabatan Kristen yang sungguh membutuhkan banyak waktu dan adalah tantangan hebat bagi kita. Sebelum membicarakan secara khusus mengenai pertobatan dan ihwal kekristenan dengan seorang sahabat, kita dapat membawa dia ke gereja atau ke suatu kebaktian lain untuk mendengarkan Injil.

4. Bersaksi

Kita juga wajib memberikan kesaksian pribadi tentang Kristus kepada sahabat kita, hal demikian juga untuk membantunya lebih memahami bagaimana Kristus bekerja di dalam kehidupan orang percaya.

\section{KESIMPULAN}

Menjadi seorang guru PAK adalah tugas yang mulia. Guru PAK seharusnya menyadari bahwa profesi ini adalah bentuk pelayanannya kepada Tuhan dan juga kepada masyarakat. Guru PAK yang melaksanakan pelayanannya dengan sungguh-sungguh, berarti ia telah menjadi jembatan bagi peserta didik maupun orang lainnya untuk dapat berjumpa dengan Kristus. Dalam melaksanakan pelayanan yang sungguh-sungguh itu, guru PAK terlebih dahulu harus memiliki kepercayaan di dalam Kristus dan sudah hidup baru.

Jika seorang guru sudah percaya sungguh kepada Yesus pasti ada kerinduan yang tak terbendung untuk membagi pengalamannya ini kepada anak didik melalui penginjilan yang dilakukannya. Imannya kepada Yesus tampak dalam sikap yang mau menginjili. Dalam kedudukannya sebagai guru agama Kristen perlu sekali ini mengembangkan sikap ini.Sisa hidupnya harus mengesampingkan dirinya sendiri. Ia harus mengurangi haknya sendiri pada waktu ia melayani orang lain. Inilah yang seharusnya menjadi ciri khas guru agama Kristen yang mau melayani bukan untuk dilayani (Mrk 10:45).

Kebesaran guru PAK tidak ditentukan oleh jabatan, kekayaan ataupun tingginya intelektualitas, melainkan oleh kerelaan dalam melayani. Jadi, guru PAK dalam melaksanakan tugas dan tanggung jawabnya haruslah dengan hati yang sungguh-sungguh, tujuannya untuk melayani dan melakukan segala pekerjaannya untuk kemuliaan nama Tuhan, itulah pelayanan Guru PAK yang sejati.

\section{DAFTAR PUSTAKA}

[1] Alkitab, Lembaga Alkitab Indonesia

[2] Boehlke, R. 2003, Sejarah Perkembangan Pikiran dan Praktek pendidikan Agama Kristen. Jakarta: BPK Gunung Mulia.

[3] Ellis, D.W. 1999. Metode Penginjilan. Jakarta: Yayasan Komunikasi Bina Kasih/OMF

[4] Homrighausen, E.G. 2014. Pendidikan Agama Kristen. Jakarta: BPK Gunung Mulia

[5] Kristianto, Paulus Lilik. 2008. Prinsip \& Praktik Pendidikan Agama Kristen. Yogyakarta: Andi Offset.

[6] Nainggolan, John M. 2008. Startegi Pendidikan Agama Kristen. Bandung: Generasi info Media.

[7] 2009. PAK Dalam Masyarakat Majemuk. Bandung: Generasi Info Media.

[8] Tomatala, Y. 1998. Penginjilan 
Masa Kini. Malang: Gandum Mas. 